\title{
RAFAEL SEGOVIA (1928-2018)
}

\author{
Fernando Escalante Gonzalbo \\ El Colegio de México \\ fescalan@colmex.mx
}

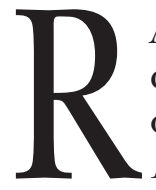

AFAEL SEGOVIA fue mi maestro. Cuando lo conocí, en 1981, ya había publicado lo fundamental de su obra académica: Tres salvaciones del siglo XVIII español, los ensayos académicos que aparecen en Lapidaria política. Seguiría publicando en la prensa, todas las semanas, los siguientes treinta años.

Con frecuencia al entrar en su oficina me lo encontraba escribiendo en uno de sus cuadernos, la letra pequeña y puntiaguda, el artículo de la semana. Y sucedía, como es natural, que en algún momento la conversación derivase hacia el tema, o más bien hacia alguno de los temas del artículo que tenía a medio escribir: hacía entonces un gesto con la mano, para abrir un paréntesis, y leía en voz alta uno o dos párrafos de lo que llevaba escrito. Al terminar, se quedaba mirando el cuaderno, como si valorase lo que acababa de leer. Espiaba mi reacción mientras leía, pero nunca pidió mi opinión sobre lo que había escrito. Sólo quería poner el texto en medio de la conversación, como para redondear su idea, y seguir.

Los artículos de prensa de Segovia, como su conversación, tenían un estilo muy particular, perfectamente reconocible, pero que me cuesta trabajo explicar. Nunca había un único tema, mejor dicho: el tema se abría en una infinidad de ramificaciones, sin que se perdiera de vista nunca el motivo central. Y esa amplitud de la mirada los hacía fascinantes. El punto de partida siempre era un episodio de la coyuntura: no le gustaban los temas abstractos, ni hablar en términos generales. La anécdota, una declaración o un nombramiento, una 
decisión, daba pie para otras más, con cuyo conjunto se iba formando el perfil de la coyuntura, que casi siempre admitía una generalización, puesta casi de pasada, y el bosquejo de un paralelismo con otras situaciones históricas, el contraste con una tesis de Jouvenel o de Lipset. Segovia siempre estaba dando clases, a su manera.

Rafael Segovia fue el fundador de la ciencia política moderna en México. Otros han tenido más fama, y da lo mismo si merecida o no, pero nadie ha tenido mayor influencia. No hace falta recordar que escribió el primer estudio empírico de la cultura política mexicana, pero sí decir que no ha sido superado, ni creo que pueda serlo. La complejidad de las clasificaciones que emplea Segovia le permiten descubrir matices extraordinariamente reveladores. Pero hay además una sabiduría histórica, política, sociológica, que hace que la explicación tenga una profundidad excepcional: casi diría, que hace que haya una verdadera explicación, donde normalmente no hay más que el repaso árido de porcentajes, tendencias, proporciones.

Para varias generaciones Rafael Segovia fue el maestro por antonomasia, al que reconocimos siempre así. A otros, algunos muy buenos, algunos muy famosos, había que identificarlos por el apellido, pero si decíamos "el profe", sin más, no había duda de que se trataba de Segovia. Y él nos distinguía a los que habíamos sido sus alumnos, que seguíamos siendo sus alumnos, manteniéndonos el trato de usted.

A veces pienso que su modelo, si hubiese tenido alguno, habría sido Alain. Maestro también toda su vida, con un intenso magisterio en la prensa también, una escritura sabia, transparente, amable: republicano, ilustrado, realista, íntegro. Segovia poseía ese conjunto de virtudes por las que en México se dice de alguien que es "institucional", y que se traduce en un acusado sentido de la responsabilidad y un muy genuino respeto por la autoridad, la legalidad, las reglas, pero que es todo lo contrario de la subordinación. Ser institucional significa que por respeto a la institución presidencial, por ejemplo, a veces es necesario discrepar del presidente -en voz alta. 
Así vi yo a Segovia, en su casa, contradecir con amabilidad, con cortesía, pero con absoluta firmeza, al presidente de la república, con la tranquila seguridad de quien no hace sino cumplir con su deber.

Rafael Segovia fue el hombre menos pretencioso que he conocido yo en el mundo académico. Nunca fingía saber algo que no sabía, ni fingía haber leído lo que no había leído, y no le costaba ningún trabajo preguntar por lo que fuera. Nunca pretendía estar al cabo de la calle. Estaba seguro de su lugar, sabía quién era. Nunca quiso ser más que nadie ni envidió a nadie: si lo pienso, acaso la envidia haya sido la emoción más remota para él.

Hablaba con franqueza, con claridad y educación, pero sin retórica. Y trataba a todo el mundo con la misma cortesía y con la misma seriedad. Tengo la impresión de que le dolía especialmente el ridículo, y por eso se cuidaba de no ridiculizar a nadie. Discutía, aunque no creo que le gustase discutir, con energía, con seriedad, con firmeza, pero sin sarcasmos.

No hablaba mucho de España, ni de la Segunda República ni de la guerra civil, salvo cuando estaba seguro de que el tema interesaba a su interlocutor. En nuestras conversaciones, siempre fui yo quien sacó el tema. Desde luego, su interés por el asunto era ilimitado, y era asombroso el detalle con que podía hablar de ello. Pero sobre todo, el proceso español le inspiraba reflexiones de un alcance mucho mayor: sobre la política, la moral, la historia, sobre México; señal, según yo, de que había pensado y seguía pensando en todo ello, constantemente. Por eso en nuestras conversaciones siempre faltaba poco para que apareciesen Azaña, Prieto, Besteiro, Negrín. Estoy seguro: la experiencia, o mejor dicho, la reflexión sobre la experiencia de la Segunda República fue la influencia decisiva para formar el carácter, la vocación y la actitud moral de Segovia. Curiosamente, lo más público de su biografía lo trataba casi como un asunto íntimo.

Rafael Segovia encarnó como nadie el espíritu de la Segunda República en el exilio, un espíritu hecho de integridad, prudencia, sentido de la responsabilidad, sobriedad, confian- 
za en las instituciones, confianza en la educación, y un profundo amor por México.

Segovia era un hombre de convicciones firmes, pero no dogmático. Y desde luego, nunca manifestó ningún afán proselitista. Nunca alzaba la voz. En su tono había siempre, cuando hablaba, un dejo de ironía que le servía para disimular las emociones. Y aunque resulte extraño en alguien que dio clases durante cincuenta años, era en el fondo sumamente tímido. Era discreto, enemigo de alardes de cualquier tipo, intelectuales o sentimentales. Los aspavientos le resultaban desagradables, y siempre recelaba de las expresiones demasiado efusivas. Era un hombre generoso, cálido, pero sobrio, de una efusividad muy medida.

Sus juicios sobre libros o autores solían ser tajantes, pero de una rara ecuanimidad. No le importaba que el autor fuese más o menos famoso, más o menos aplaudido, él tenía su opinión, clarísima. Y sobre dos libros de un mismo autor, podía ser enteramente distinta: juzgaba el libro, sin más. Lo recuerdo alguna vez, hablando de un libro de Moses Finley: "Es el libro más ridículo que he leído". De Baroja, por ejemplo, habría leído acaso cincuenta libros, si no más, y hablamos de él con frecuencia, recordaba con afecto la visita que había hecho a Julio Caro en la casa de Itzea; pero lo recuerdo también leyendo uno de los últimos, un volumen con artículos de prensa de Baroja, lo estoy viendo cerrar el libro con fuerza: "¡Pero cómo se puede ser tan burro...!"

Estaba enterado de lo que se publicaba, pero por regla general prefería leer o releer libros viejos: Albert Thibaudet, Lewis Namier, Ivor Jennings, libros de historia: "Los libros empíricos, me dijo alguna vez, son los únicos que duran”. Era gran lector de literatura también, tenía debilidad por Apollinaire, Quevedo, Cèline, y podía hablar de cosas tan grises y remotas como la poesía española del siglo XIX, pero no le interesaba mucho la literatura contemporánea.

Cuando yo conocí a Rafael Segovia, El Colegio de México era una institución sui generis, en la que pesaba sobre todo la personalidad de los profesores, de algunos profesores, mucho 
más que la formalidad burocrática de la vida colegiada. En ese mundo se imponía naturalmente la personalidad de Segovia, porque representaba una idea de la institución, una idea de la educación superior, una idea del país -la que se había forjado en 1940. No hay un pensamiento de Rafael Segovia, no hay una teoría, un método, sino algo mucho más amplio y más sólido: una actitud y una manera de mirar el mundo. En ella nos reconocemos los que fuimos sus alumnos.

Frente a cualquier idea, frente a cualquier argumento, de quien fuese, tenía siempre reparos, dudas. La mayoría de las veces, cuando aventuraba yo una explicación o una conjetura, la conversación comenzaba con un: "No, Escalante, no es asî”. Y sus reparos obligaban siempre a pensar las cosas de nuevo. Sobre todo, Segovia procuraba moderar, matizar, cualquier afirmación demasiado rotunda.

Su interés por la política era inagotable, apasionado, íntimo. Y le interesaba todo: las noticias, las leyes, las opiniones, los chismes. En su cabeza, todo formaba parte de un formidable mural, con un detalle de exactitud asombrosa. Como si fuese lo más natural del mundo, pasaba de un desliz en una declaración del presidente a una frase de Maquiavelo, un episodio de la Revolución Francesa o de la Guerra de los Treinta Años.

Segovia hablaba siempre con muy auténtico respeto de sus maestros: Edmundo O'Gormann, Jean-Baptiste Duroselle, también de Daniel Cosío Villegas, y con un hondo amor por su hermano Tomás. Tenía siempre presente que en su vínculo con ellos se fraguaba una continuidad larguísima, y que no había nada más importante. Su amor por el Colegio era el amor por una idea. El Colegio era para Segovia el rigor, la exigencia, la responsabilidad, el patriotismo, y sobre todo la preservación de esa continuidad, esa forma singular de la filiación que es el magisterio -una forma más modesta, íntima, más entrañable de la inmortalidad.

Sobrellevaba los resentimientos, las mezquindades, la ruindad que es tan abundante en el medio con un distanciamiento irónico, pero nada estoico. En sus últimos años, la 
decadencia de todo aquello por lo que había trabajado le dolía profundamente. Se volvió más retraído, taciturno, el humor de sus artículos se volvió más ácido. Pero nunca tuvo un talante sombrío. Siempre me recibía en su oficina con la misma sonrisa, luminosa, abriendo enormemente los ojos, con los brazos extendidos, y me daba un beso -dispuesto a hablar de lo que fuera.

Segovia respetaba siempre el trabajo serio, la conciencia profesional, la responsabilidad, tanto como despreciaba la impostura, la fatuidad, la tartufería, el moralismo estridente de los intelectuales detrás del que adivinaba un oportunismo cínico y ventajista. En los políticos, sobre todo detestaba la irresponsabilidad, la ignorancia, la improvisación, la falta de oficio.

En su casa, con Paule, era un anfitrión espléndido, que no hacía alardes, con una generosidad que resultaba perfectamente natural. Yo sé que la expresión es anticuada, porque la idea, la condición es anticuada, pero es así: Rafael Segovia era un caballero. Entre sus alumnos, los que sabíamos que le debíamos tanto, Rafael Segovia inspiraba respeto, también afecto, y sobre todo lealtad. Sé que podría hablar a nombre de muchos más: Rafael Segovia ha sido, de lejos, la personalidad más influyente en mi vida profesional. Pero recibí también de él lecciones morales, ejemplos, y algunos de los consejos personales más valiosos que me han dado, y que quisiera ser capaz de transmitir. En el sentido más grave de la palabra, Rafael Segovia fue mi maestro. 